\title{
A Polymerase Chain Reaction-Based Method to Specifically Detect Alternaria alternata Apple Pathotype (A. mali), the Causal Agent of Alternaria Blotch of Apple
}

\author{
R. D. Johnson, L. Johnson, K. Kohmoto, H. Otani, C. R. Lane, and M. Kodama
}

First, second, third, fourth, and sixth authors: Laboratory of Plant Pathology, Faculty of Agriculture, Tottori University, Tottori 680-8553, Japan; fifth author: Central Science Laboratory, Sand Hutton, York, YO41 1LZ, UK.

Current address of R. D. Johnson and L. Johnson: Division of Plant and Soil Sciences, 401 Brooks Hall, West Virginia University, Morgantown 26506.

Accepted for publication 18 May 2000.

\begin{abstract}
Johnson, R. D., Johnson, L., Kohmoto, K., Otani, H., Lane, C. R., and Kodama, M. 2000. A polymerase chain reaction-based method to specifically detect Alternaria alternata apple pathotype (A. mali), the causal agent of Alternaria blotch of apple. Phytopathology 90:973-976.

Alternaria alternata apple pathotype (previously A. mali) causes Alternaria blotch on susceptible apple cultivars through the production of a host-specific toxin, AM-toxin. Identification of some Alternaria species,

difficult due to a high level of variability which extends even to nonpathogenic isolates. We have recently cloned and characterized a gene (AMT) that plays a crucial role in AM-toxin biosynthesis and demonstrated that it is only present in isolates of A. alternata apple pathotype. Using primers designed for the $A M T$ gene, we developed a polymerase chainreaction-based method to specifically detect AM-toxin producing isolates of A. alternata apple pathotype.
\end{abstract} especially those that produce host-specific toxins, has been extremely

The genus Alternaria encompasses both nonpathogenic and pathogenic species. Many of the species comprise different pathotypes of A. alternata (Fries) Keissler, each of which has a distinct and limited host range characterized by the production of hostspecific toxins (HSTs) essential for pathogenesis $(11,20,24)$. The mechanisms of host-selective pathogenesis through the participation of HSTs is well understood $(20,32,39)$ and about 20 HSTs have been documented (38), of which at least nine are from A. alternata pathotypes (24). A. alternata apple pathotype (previously described as a distinct virulent form of $A$. mali Roberts) causes Alternaria blotch of apple on a narrow range of susceptible apple cultivars through the production of a host-specific AM-toxin (12). This disease is of worldwide importance $(7,31)$ and is one of the most serious diseases of apple in Japan $(10,30)$. AM-toxin consists of a four-membered cyclic depsipeptide (20,23,37). Physiological and ultrastructural studies suggest that susceptible cultivars of apple have two primary sites for the toxin; one on the plasma membrane and one on the chloroplast $(11,20,24,25)$.

Identification of some Alternaria species, especially those that produce HSTs, has been extremely difficult due to a high level of variability in the formation and morphology of conidia, which extends even to nonpathogenic isolates $(28,34,40)$. Recent work has indicated that Alternaria pathogens which produce HSTs are pathogenic variants within a single variable species, A. alternata $(14,15)$.

Because apple blotch is widespread and has the potential to increase in incidence on susceptible apple cultivars, many of which are still grown commercially (7), it is essential to develop a fast and reliable method to differentiate this pathogen from other A. alternata pathotypes and nonpathogenic isolates. The polymerase chain reaction (PCR) has been shown to be useful as a diagnostic

Corresponding author: M. Kodama; E-mail address: mk@muses.tottori-u.ac.jp

Publication no. P-2000-0630-01R

(C) 2000 The American Phytopathological Society
Additional keywords: host-selective toxin, molecular diagnostics. tool for numerous fungal pathogens which are difficult to differentiate using conventional techniques $(4,6,8,16,18,27,36)$. We have recently cloned a gene, AMT (GenBank accession no. AF184074), which has a crucial role in AM-toxin biosynthesis (9) and demonstrated that it is specific to the apple pathotype. AMT has an open reading frame of 13.1 kilobases (kb) in length which contains no introns. The derived amino acid sequence has a predicted molecular mass of $474 \mathrm{kDa}$ and shows high homology to other cyclic peptide synthetase enzymes. Four catalytic domains, responsible for the activation of each residue in AM-toxin, were identified in $A M T$. This paper describes the use of a PCR-based technique, using primers designed for the cloned $A M T$ gene, to specifically detect $A$. alternata apple pathotypes in field isolates of Alternaria pathogens.

\section{MATERIALS AND METHODS}

Fungal strains and culture conditions. Fungal strains used in this study are listed in Table 1. In addition, some of these isolates were described previously (2). All isolates were maintained on potato dextrose agar (Difco, Detroit, MI) slopes or as $15 \%$ glycerol spore suspensions at $-80^{\circ} \mathrm{C}$.

Leaf Necrosis Bioassay. For a leaf necrosis bioassay, cultures of representative A. alternata pathotypes and nonpathogenic $A$. alternata were grown at $26^{\circ} \mathrm{C}$ in $50 \mathrm{ml}$ of Czapex-Dox medium (Oxoid, Hampshire, UK) supplemented with a $0.5 \%$ yeast extract (Difco) for 6 days with no shaking. The culture filtrate was collected and $20 \mu \mathrm{l}$ was placed on the underside of a young leaf of the highly susceptible cv. Indo which had been slightly wounded by scratching the epidermis. Leaves were incubated overnight in the dark at $26^{\circ} \mathrm{C}$ and were assessed for necrosis after $24 \mathrm{~h}$.

DNA manipulations. Genomic DNA was extracted as described previously (1), and nucleic acid manipulations followed standard procedures (29). Restriction digestions were carried out using $5 \mu \mathrm{g}$ of DNA according to the manufacturer's instructions (Toyobo, Tokyo) and fractionated in $0.8 \%$ agarose gels. Frac- 
tionated DNA was transferred to Hybond-N membranes (Amersham Pharmacia Biotech, Buckinghamshire, UK) by capillary transfer under alkaline conditions (26). A $0.25-\mathrm{kb}$ DIG-labeled probe (300-1), corresponding to positions 2656-2914 in AMT, was generated by PCR using a DIG-DNA labeling and detection kit (Boehringer Mannheim GmbH, Mannheim, Germany). HindIII genomic digests of representative A. alternata pathotypes and nonpathogenic A. alternata were hybridized and washed under high stringency following the manufacturer's instructions.

Polymerase chain reaction. A pair of $A M T$-specific primers (LinF1, 5'-TAT CGC CTG GCC ACC TAC GC-3'; LinR, 5'-TGG CCA CGA CAA CCC ACA TA-3') whose target sequence corresponds to positions 8017-8036 (LinF1) and 8493-8512 (LinR) within the $A M T$ gene (Genbank accession no. AF184074) or $\beta$ tubulin-specific primers $(\beta$-tub1, 5'-TCC GTC GTG CCT TCC CCC AAG GTC TCC GAC-3'; $\beta$-tub2, 5'-GGA GCG AAT CCG ACC ATG AAG AAG TGG AGA-3') for positive controls, were used in PCR experiments with genomic DNA of the appropriate Alternaria isolate under the following conditions: Twenty nanograms of genomic DNA was added to a $20-\mu 1$ reaction containing: dNTPs at a final concentration of $250 \mu \mathrm{M}$ (Takara, Tokyo), 1× PCR reaction buffer (Takara), primers at a final concentration of $1 \mu \mathrm{M}$ (Pharmacia Biotech) and 1.0 unit of Taq DNA polymerase (Takara). PCR was performed in a GeneAmp PCR system 9600 (Perkin-Elmer, Norwalk, CT) with an initial step of $5 \mathrm{~min}$ at $95^{\circ} \mathrm{C}$ followed by 30 cycles of $30 \mathrm{~s}$ at $94^{\circ} \mathrm{C}, 30 \mathrm{~s}$ at $65^{\circ} \mathrm{C}, 45 \mathrm{~s}$ at $72^{\circ} \mathrm{C}$, and a final step of $7 \mathrm{~min}$ at $72^{\circ} \mathrm{C}$.

\section{RESULTS}

Leaf necrosis bioassay. Culture filtrates of A. alternata pathotypes (apple, Japanese pear, tomato, and strawberry) and a nonpathogenic A. alternata were tested for the presence of AMtoxin using a leaf necrosis bioassay (Fig. 1 and Table 1), as described in the methods. Only A. alternata apple pathotype gave a positive result using the susceptible apple cv. Indo, demonstrating the host-specific nature of this toxin, which has been previously described (12).

Southern analysis. Southern analysis was carried out using a 0.25 -kb fragment (300-1) of the cloned $A M T$ gene as a probe to Hind III genomic digests of different A. alternata pathotypes and nonpathogenic isolates. The $A M T$ probe hybridized only to the apple pathotype (Fig. 2), and together with the bioassay data provides strong evidence that strains unable to produce AM-toxin contain no homologs to $A M T$. Therefore, running a PCR with primers designed for the $A M T$ gene should be a good strategy to specifically identify the A. alternata apple pathotype.

Polymerase chain reaction. Primers designed for the cloned $A M T$ gene (see methods) were used in a PCR reaction with $20 \mathrm{ng}$ of genomic DNA from various A. alternata pathogens (including five pathotypes), nonpathogenic A. alternata, and $A$. brassicae using conditions described in the methods. A PCR product of the expected size $(0.5-\mathrm{kb})$ was only amplified from A. alternata apple pathotype. No other products were identified from different $A$. alternata pathotypes, nonpathogenic A. alternata, and other Alternaria species pathogenic on a range of different hosts (Fig. 3 and Table 1). A. brassicae, which produces the HST destruxin B (3), that is similar in structure to AM-toxin and is probably synthesized via a similar biosynthetic pathway, also gave no PCR product. All isolates amplified a 0.35 -kb product using primers to the $\beta$-tubulin gene (Fig. 3) proving that negative amplification with the $A M T$ primers was not due to poor template DNA. These results clearly demonstrate that PCR with $A M T$ gene-specific primers is a reliable technique to specifically detect $A$. alternata apple pathotype, the causal agent of Alternaria blotch of apple.

\section{DISCUSSION}

The genus Alternaria encompasses both nonpathogenic and pathogenic species. Seven of these pathogens cannot be distin-

TABLE 1. Alternaria strains, AM-toxin bioassay and polymerase chain reaction

\begin{tabular}{|c|c|c|c|c|c|c|}
\hline Strain & Disease & HST & Source & Pathogenicity $^{\mathrm{a}}$ & $\mathrm{PCR}^{\mathrm{b}}$ & Reference \\
\hline \multicolumn{7}{|l|}{ A. alternata } \\
\hline Apple pathotype & Alternaria blotch of apple & AM-toxin & & & & \\
\hline M-71 & & & Japan & + & + & Akamatsu et al. 1999 \\
\hline FIV-Cont45 & & & Japan & + & + & Akamatsu et al. 1999 \\
\hline O-159 & & & Japan & + & + & Akamatsu et al. 1999 \\
\hline O-210 & & & Japan & + & + & Akamatsu et al. 1999 \\
\hline CSL-635 & & & USA & + & + & This study \\
\hline CSL-1166 & & & USA & + & + & This study \\
\hline CSL-1175 & & & USA & + & + & This study \\
\hline CSL-1177 & & & USA & + & + & This study \\
\hline Japanese pear pathotype & Black spot of Japanese pear & AK-toxin & & & & \\
\hline No.15A & & & Japan & - & - & Akamatsu et al. 1999 \\
\hline Strawberry pathotype (f. sp. fragariae) & Alternaria black spot of strawberry & AF-toxin & & & & \\
\hline $\mathrm{M}-30$ & & & Japan & - & - & Akamatsu et al. 1999 \\
\hline Tomato pathotype (f. sp. lycopersici) & Alternaria stem canker of tomato & $\mathrm{A}(\mathrm{A}) \mathrm{L}$-toxin & & & & \\
\hline As-27 & & & USA & - & - & \\
\hline Tobacco pathotype & Brown spot of tobacco & AT-toxin & & & & \\
\hline ATL-5 & & & Japan & - & - & Akamatsu et al. 1999 \\
\hline \multicolumn{7}{|l|}{ Non-pathogenic } \\
\hline O-94 & & & Japan & - & - & Akamatsu et al. 1999 \\
\hline EGS35-193 & & & USA & - & - & Akamatsu et al. 1999 \\
\hline \multicolumn{7}{|l|}{ European pear isolate } \\
\hline CSL648 & $\mathrm{UC}^{\mathrm{c}}$ & $\mathrm{UC}$ & Portugal & - & - & This study \\
\hline \multicolumn{7}{|l|}{ Chinese pear isolate } \\
\hline CSL704 & $\mathrm{UC}$ & $\mathrm{UC}$ & China & ND & - & This study \\
\hline \multicolumn{7}{|l|}{ Wheat Isolate } \\
\hline CSL325 & $\mathrm{UC}$ & $\mathrm{UC}$ & Unknown & - & - & This study \\
\hline \multicolumn{7}{|l|}{ A. brassicae } \\
\hline MAFF712079 & Gray spot of Brassica & Destruxin B & Japan & - & - & Bains \& Tewart 1987 \\
\hline
\end{tabular}

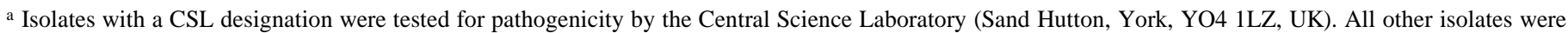
tested for pathogenicity using a leaf necrosis bioassay as described. + designates pathogenic; - designates nonpathogenic; ND designates not done.

b Genomic DNA (20 ng) was used in a polymerase chain reaction with $A M T$ specific primers. + designates amplification; - designates no amplification.

c Uncharacterized. 
guished from ubiquitous saprophytic A. alternata (Fries) Keissler $(5,17,33)$ on the basis of conidial morphology $(19,21)$ but have been designated as distinct pathotypes based on their unique pathogenicity $(19,21,22)$. These pathotypes have a distinct and limited host range characterized by the production of HSTs essential for pathogenesis $(11,20,24)$. A. alternata apple pathotype produces the host-specific AM-toxin, and causes Alternaria blotch, a disease of

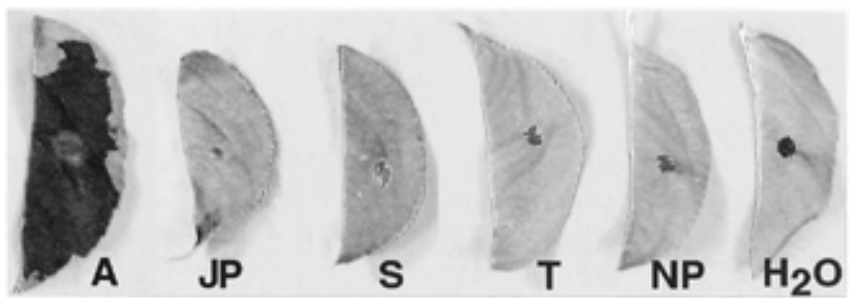

Fig. 1. Leaf necrosis bioassay of Alternaria alternata pathotypes and nonpathogenic A. alternata. Twenty microliters of culture filtrate was placed on the underside of a young leaf of the highly susceptible apple cv. Indo. A, apple pathotype (M-71); JP, Japanese pear pathotype (No.15A); S, strawberry pathotype (M-30); T, tomato pathotype (As-27); NP, non-pathogenic $A$. alternata $(\mathrm{O}-94) ; \mathrm{H}_{2} \mathrm{O}$, water.

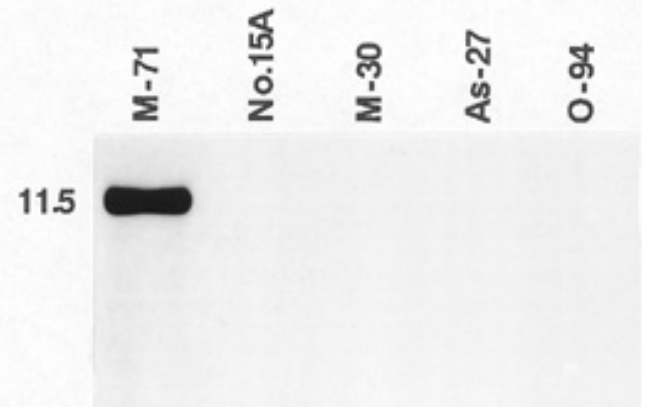

Fig. 2. Southern blot analysis of Alternaria alternata pathotypes using AMT probe 300-1. Total DNA was digested with HindIII, separated in a $0.8 \%$ agarose gel and hybridized to DIG-dUTP labeled 300-1 from A. alternata apple pathotype. Lane 1, apple pathotype (M-71); Lane 2, Japanese pear pathotype (No.15A); Lane 3, strawberry pathotype (M-30); Lane 4, tomato pathotype (As-27); Lane 5, non-pathogenic isolate (O-94). Size is in kilobases.

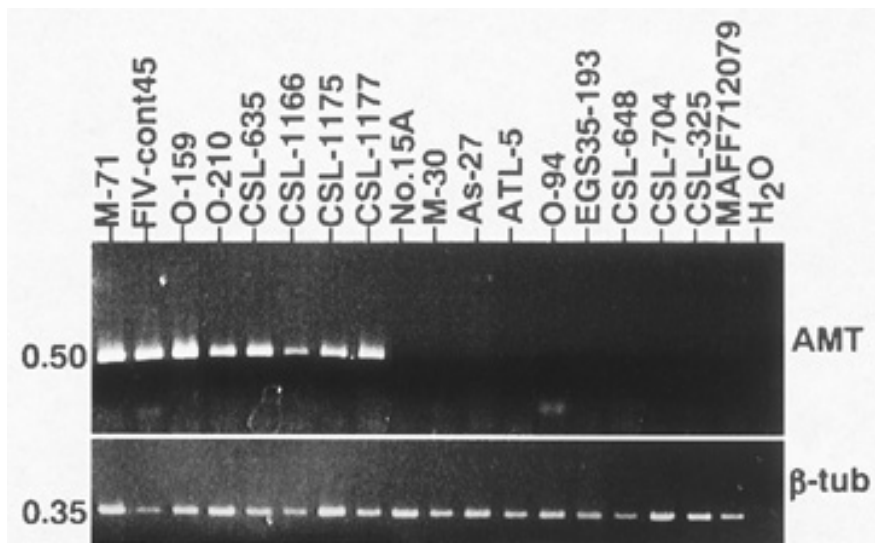

Fig. 3. Polymerase chain reaction using Alternaria alternata pathotypes, non-pathogenic A. alternata and other Alternaria pathogens. AMT specific primers (LinF1, 5'-TAT CGC CTG GCC ACC TAC GC-3'; LinR, 5'-TGG CCA CGA CAA CCC ACA TA-3') amplified a 0.5-kb product. Beta-tubulin specific primers ( $\beta$-tub1, 5'-TCC GTC GTG CCT TCC CCC AAG GTC TCC GAC-3'; $\beta$-tub2, $5^{\prime}$-GGA GCG AAT CCG ACC ATG AAG AAG TGG AGA-3') were used as a positive control and amplified a $0.35-\mathrm{kb}$ product from all isolates. $\mathrm{H}_{2} \mathrm{O}$ contains all reagents except DNA and acts as a negative control. Sizes are in kilobases. worldwide importance $(7,31)$ and one of the most serious diseases of apple in Japan $(10,30)$, on a narrow range of susceptible apple cultivars (12).

The proposal that plant pathogenic A. alternata should be classified by pathotype $(19,21,22)$ has not been widely accepted, partly because conventional classification of the imperfect fungus Alternaria depends on variation in formation and morphology of conidia $(28,33,40)$. Molecular approaches to elucidate the taxonomy of Alternaria have also been used. DNA-DNA reassociation analysis between HST-producing A. alternata and nonpathogenic A. alternata suggested a close relationship (13). Restriction fragment length polymorphism (RFLP) analysis revealed that HST producing A. alternata could not be separated from nonpathogenic A. alternata (14). Comparison of the internal transcribed spacer regions (ITS1 and ITS2) of rDNA supported these results (15).

Identification of these important pathogens is therefore a lengthy and time-consuming process involving a combination of pathogenicity testing and conidial morphology analysis. The PCR has been shown to be useful as a diagnostic tool for numerous fungal pathogens which are difficult to differentiate using conventional techniques $(4,6,8,16,18,27,36)$. Because the disease causing ability of the different $A$. alternata pathotypes is related to the production of HSTs, cloning of the genes required for their biosynthesis will not only further our understanding of the molecular basis of host specificity but will also provide molecular probes for diagnostic techniques. Recently we have cloned a gene, AMT (Genbank accession no. AF184074), from A. alternata apple pathotype involved in AM-toxin biosynthesis and shown it to be highly specific to the apple pathotype (9). Using primers designed for the $A M T$ gene we have developed a PCR-based method to specifically identify A. alternata apple pathotype from other A. alternata pathotypes, nonpathogenic A. alternata, and other disease causing Alternaria species (Fig. 3). As other genes, from other A. alternata pathotypes, involved in HST production become characterized at the molecular level, similar diagnostic techniques will become available to identify these pathogens. Already, the genes for $A K T 1$ and $A K T 2$ involved in AK-toxin production from $A$. alternata Japanese pear pathotype have been cloned and shown to be specific to this pathotype (35).

Although the work here uses total DNA as a template for PCR, direct amplification from diseased plant material should be possible and we are currently refining the PCR procedure described here for this purpose.

\section{ACKNOWLEDGMENTS}

We acknowledge K. Hughes and P. Beales (Central Science Laboratory) for assistance during the work, and H. Tabira (Laboratory of Plant Biotechnology, Tottori Horticultural Experimental Station, Kura-yoshi 682 , Japan) for kindly donating apple leaves for use in bioassays. This work was supported by a Japan Society for the Promotion of Science (JSPS) fellowship to R. D. Johnson and grants in aid for scientific research from the Ministry of Education, Science, Sports and Culture of Japan (no. 97131 to R. D. Johnson, no. 08044207 to K. Kohmoto, and no. 11660046 to M. Kodama).

\section{LITERATURE CITED}

1. Akamatsu, H., Itoh, Y., Kodama, M., Otani, H., and Kohmoto, K. 1997. AAL-toxin-deficient mutants of Alternaria alternata tomato pathotype by restriction enzyme-mediated integration. Phytopathology 87:967-972.

2. Akamatsu, H., Taga, M., Kodama, M., Johnson, R., Otani, H., and Kohmoto, K. 1999. Molecular karyotypes for Alternaria plant pathogens known to produce host-specific toxins. Curr. Genet. 35:647-656.

3. Bains, P. S., and Tewart, J. P. 1987. Purification, chemical characterization and host-specificity of the toxin produced by Alternaria brassicae. Physiol. Mol. Plant Pathol. 30:259-271.

4. Brown, A. E., Muthumeenakshi, S., Sreenivasaprasad, S., Mills, P. R., and Swinburne, T. R. 1993. A PCR primer-specific to Cylindrocarpon heteronema for detection of the pathogen in apple wood. FEMS Microbiol. Lett. 15:117-120. 
5. Ellis, M. B. 1971. Dermatiaceous hyphomycetes. Commonwealth Mycological Institute, Kew, England.

6. Fernandez, D., Ouinten, M., Tantaoui, A., Geiger, J. P., Daboussi, M. J., and Langin, T. 1998. Fot 1 insertions in the Fusarium oxysporum f. sp. albedinis genome provide diagnostic PCR targets for detection of the date palm pathogen. Appl. Environ. Microbiol. 64:633-636.

7. Filajdic, N., and Sutton, T. B. 1991. Identification and distribution of Alternari mali on apples in North Carolina and susceptibility of different varieties of apples to Alternaria blotch. Plant Dis. 75:1045-1048.

8. Fulton, C. E., and Brown, A. E. 1997. Use of SSU rDNA group-I intron to distinguish Monilinia fructicola from $M$. laxa and M. fructigena. FEMS Microbiol. Lett. 157:307-312.

9. Johnson, R. D., Johnson, L., Itoh, Y., Kodama, M., Otani, H., and Kohmoto, K. 2000. Cloning and characterization of a cyclic peptide synthetase gene from Alternaria alternata apple pathotype whose product is involved in AM-toxin synthesis and pathogenicity. Mol. Plant-Microbe Int. 13:742-753.

10. Kiyosawa, S. 1977. Some examples of pest and disease epidemics in Japan and their causes. Pages 34-35 in: The Genetic Basis of Epidemics in Agriculture. P. Day, ed. Ann. N. Y. Acad. Sci. 287.

11. Kohmoto, K., and Otani, H. 1991. Host recognition by toxigenic plant pathogens. Experientia 47:755-764

12. Kohmoto, K., Taniguchi, T., and Nishimura, S. 1974. Correlation between the susceptibility of apple cultivars to Alternaria mali and their sensitivity to AM-toxin I. Ann. Phytopathol. Soc. Jpn. 43:65-66.

13. Kuninaga, S., and Yokosawa, R. 1987. Studies on the taxonomy of plant pathogenic fungi by a comparison of DNA homology. I. Genetic relatedness among species in the genus Alternaria (in Japanese). Ann. Phytopathol. Soc. Jpn. 53:368-369.

14. Kusaba, M., and Tsuge, T. 1994. Nuclear ribosomal DNA variation and pathogenic specialization in Alternaria fungi known to produce hostspecific toxins. Appl. Environ. Microbiol. 60:3055-3062.

15. Kusaba, M., and Tsuge, T. 1995. Phylogeny of Alternaria fungi known to produce host-specific toxins on the basis of variation in internal transcribed spacers of ribosomal DNA. Curr. Genet. 28:491-498.

16. Li, K. N., Rouse, D. I., and German, T. L. 1994. PCR primers that allow intergeneric differentiation of ascomycetes and their application to Verticillium spp. Appl. Environ. Microbiol. 60:4324-4331.

17. Neergaard, P. 1945. Danish species of Alternaria and Stemphylium, Einar Munksgaard, Copenhagen.

18. Niessen, M. L., and Vogel, R. F. 1998. Group specific PCR-detection of potential trichothecene-producing Fusarium-species in pure cultures and cereal samples. Syst. Appl. Microbiol. 21:618-631.

19. Nishimura, S. 1980. Host-specific toxins from Alternaria alternata: problems and prospects. Proc. Japan Acad. 56(B):362-366.

20. Nishimura, S., and Kohmoto, K. 1983. Host-specific toxins and chemical structures from Alternaria species. Annu. Rev. Phytopathol. 21:87-116.

21. Nishimura, S., Kohmoto, K., Otani, H., Ramachandran, P., and Tamura, F. 1982. Pathological and epidemiological aspects of Alternaria alternata infection depending on a host-specific toxin. Pages 199-214 in: Plant Infection: The Physiological and Biochemical Basis. A. Asada, W. R. Bushnell, S. Ouchi, and C. P. Vance, eds. Japan Scientific Societies Press, Tokyo/Springer-Verlag, Berlin, Heidelberg, New York.
22. Nishimura, S., Sugihara, M., Kohmoto, K., and Otani, H. 1978. Two different phases in pathogenicity of the Alternaria pathogen causing black spot disease of Japanese pear. J. Fac. Agric. Tottori Univ. 13:1-10.

23. Okuno, T., Ishita, Y., Sawai, K., and Matsumoto, T. 1974. Characterization of alternariolide, a host-specific toxin produced by Alternaria mali Roberts. Chem. Lett. 1974:635-638.

24. Otani, H., Kohmoto, K., and Kodama, M. 1995. Alternaria toxins and their effects on host plants. Can. J. Bot. 73(Suppl. 1):S453-S458.

25. Park, P., Nishimura, S., Kohmoto, K., Otani, H., and Tsujimoto, K. 1981. Two action sites of AM-toxin I produced by apple pathotype of Alternaria alternata in host cells: an ultrastructural study. Can. J. Bot. 59:301-310.

26. Reed, K. C., and Mann, D. A. 1985. Rapid transfer of DNA from agarose gels to nylon membranes. Nucleic Acids Res. 13:7207-7221.

27. Rollo, F., Salvi, R., and Torchia, P. 1990. Highly sensitive and fast detection of Phoma tracheiphila by polymerase chain reaction. Appl. Microbiol. Biotechnol. 32:572-576.

28. Rotem, J. 1994. The Genus Alternaria: Biology, Epidemiology and Pathogenicity. American Phytopathological Society, St. Paul, MN.

29. Sambrook, J., Fritsch, E. F., and Maniatis, T. A. 1989. Molecular Cloning: A Laboratory Manual. Second ed. Cold Spring Harbor Laboratory, Cold Spring Harbor, NY.

30. Sawamura, K. 1966. Studies on spotted disease of apples. 6. On the hostspecific toxin of Alternaria mali Roberts. Bull. Hortic. Res. Stan. Japan, Ser. C. 4:43-59.

31. Sawamura, K. 1990. Alternaria blotch. Pages 24-25 in: Compendium of Apple and Pear Diseases. A. L. Jones and H. Aldwinckle, eds. American Phytopathological Society, St. Paul, MN.

32. Scheffer, R. P., and Livingston, R. S. 1984. Host-selective toxins and their role in plant diseases. Science 223:415-419.

33. Simmons, E. G. 1967. Typification of Alternaria, Stemphylium, and Uloclladium. Mycologia 59:67-92.

34. Simmons, E. G. 1992. Alternaria taxonomy: current status, viewpoint, challenge. Pages 1-35 in: Alternaria: Biology, Plant Diseases and Metabolites. J. Chelkowski and A. Visconti, eds. Elsevier, Amsterdam.

35. Tanaka, A., Shiotani, H., Yamamoto, M., and Tsuge, T. 1999. Insertional mutagenesis and cloning of the genes required for biosynthesis of the host-specific AK-toxin in the Japanese pear pathotype of Alternaria alternata. Mol. Plant-Microbe Interact. 12:691-702.

36. Taylor, J. L. 1993. A simple, sensitive, and rapid method for detecting seed contaminated with highly virulent Leptosphaeria maculans. Appl. Environ. Microbiol. 59:3681-3685.

37. Ueno, T., Nakashima, T., Uemoto, M., Fukami, H., Lee, S. N., and Izumiya, N. 1977. Mass spectrometry of Alternaria mali toxins and related cyclodepsipeptides. Biomed. Mass Spectrom. 4:134-142.

38. Walton, J. D. 1996. Host-selective toxins: agents of compatibility. Plant Cell 8:1723-1733

39. Yoder, O. C. 1980. Toxins in pathogenesis. Annu. Rev. Phytopathol. 18:103-29

40. Yu, S. H. 1992. Occurrence of Alternaria species in countries of the Far East and their taxonomy. Pages 37-62 in: Alternaria: Biology, Plant Diseases and Metabolites. J. Chelkowski and A. Visconti, eds. Elsevier, Amsterdam. 